\title{
Article \\ Distinguishing Incubation and Acute Disease Stages of Mild-to-Moderate COVID-19
}

\author{
Michael Müller ${ }^{1,+}$, Johann Volzke ${ }^{1, *+\dagger} \mathbb{D}$, Behnam Subin ${ }^{2}$, Christian Johann Schmidt ${ }^{1}$, Hilte Geerdes-Fenge ${ }^{3}$, \\ Emil Christian Reisinger ${ }^{3}$ and Brigitte Müller-Hilke ${ }^{1, * \mathbb{D}}$
}

1 Core Facility for Cell Sorting and Cell Analysis, Rostock University Medical Center, 18057 Rostock, Germany; michael.mue@t-online.de (M.M.); Christian.Schmidt3@med.uni-rostock.de (C.J.S.)

2 Department of Cardiology, Rostock University Medical Center, 18057 Rostock, Germany; behnam.subin@med.uni-rostock.de

3 Department of Tropical Medicine and Infectious Diseases, Rostock University Medical Center, 18057 Rostock, Germany; hilte.geerdes-fenge@med.uni-rostock.de (H.G.-F.); Emil.Reisinger@med.uni-rostock.de (E.C.R.)

* Correspondence: johann.volzke@med.uni-rostock.de (J.V.); brigitte.mueller-hilke@med.uni-rostock.de (B.M.-H.); Tel.: +49-381-494-5881 (J.V.)

+ These authors contributed equally to this work.

check for

updates

Citation: Müller, M.; Volzke, J.; Subin, B.; Schmidt, C.J.; Geerdes-Fenge, H.; Reisinger, E.C.; Müller-Hilke, B Distinguishing Incubation and Acute Disease Stages of Mild-to-Moderate COVID-19. Viruses 2022, 14, 203. https://doi.org/10.3390/v14020203

Academic Editors:

Luis Martinez-Sobrido and

Fernando Almazan Toral

Received: 6 January 2022

Accepted: 19 January 2022

Published: 20 January 2022

Publisher's Note: MDPI stays neutral with regard to jurisdictional claims in published maps and institutional affiliations.

Copyright: (C) 2022 by the authors. Licensee MDPI, Basel, Switzerland. This article is an open access article distributed under the terms and conditions of the Creative Commons Attribution (CC BY) license (https:// creativecommons.org/licenses/by/ $4.0 /)$.

\begin{abstract}
While numerous studies have already compared the immune responses against SARS-CoV2 in severely and mild-to-moderately ill COVID-19 patients, longitudinal trajectories are still scarce. We therefore set out to analyze serial blood samples from mild-to-moderately ill patients in order to define the immune landscapes for differently progressed disease stages. Twenty-two COVID-19 patients were subjected to consecutive venipuncture within seven days after diagnosis or admittance to hospital. Flow cytometry was performed to analyze peripheral blood immune cell compositions and their activation as were plasma levels of cytokines and SARS-CoV-2 specific immunoglobulins. Healthy donors served as controls. Integrating the kinetics of plasmablasts and SARS-CoV-2 specific antibodies allowed for the definition of three disease stages of early COVID-19. The incubation phase was characterized by a sharp increase in pro-inflammatory monocytes and terminally differentiated cytotoxic T cells. The latter correlated significantly with elevated concentrations of IP-10. Early acute infection featured a peak in PD- $1^{+}$cytotoxic T cells, plasmablasts and increasing titers of virus specific antibodies. During late acute infection, immature neutrophils were enriched, whereas all other parameters returned to baseline. Our findings will help to define landmarks that are indispensable for the refinement of new anti-viral and anti-inflammatory therapeutics, and may also inform clinicians to optimize treatment and prevent fatal outcomes.
\end{abstract}

Keywords: SARS-CoV-2; COVID-19; disease phases; plasmablasts; cytotoxic T cells; IP-10; acute infection; antibodies

\section{Introduction}

The severe acute respiratory syndrome coronavirus type 2 (SARS-CoV-2) is a highly infectious and rapidly transmittable $\beta$-coronavirus that led to the global pandemic of coronavirus disease 2019 (COVID-19). As of summer 2021, more than 180 million people were infected, with almost 4 million casualties worldwide [1,2]. Of great concern are new virus variants that emerge periodically and exhibit augmented pandemic potentials, can cause infection of individuals vaccinated against the original strain, and re-infect patients previously recovered from COVID-19 [3,4].

COVID-19 is characterized by a diverse collection of isolated or combined symptoms ranging from mild to severe to life-threatening. While mild disease may proceed asymptomatic or show mere signs of a common cold, moderate and severe COVID-19 present with symptoms that range from fever, malaise and fatigue to neurological, dermatological, gastrointestinal and pulmonary manifestations [5]. Pneumonia may lead to 
an acute respiratory distress syndrome (ARDS), necessitating oxygen supplementation and mechanical ventilation [6,7]. Immense effort has been put into the pathophysiological and immunological profiling of the host reaction to the disease [8,9]. Thus, a dysregulated host immune response was identified that causes a life-threatening cytokine storm and subsequent immune paralysis, leading to multiple organ failure and death. And even though mild-to-moderate COVID-19 does not seem to be associated with a fulminant immune activation, more and more data point to long lasting infection related sequelae including persisting nausea, fatigue and loss of smell and taste in up to $30 \%$ of patients who recovered from COVID-19 [10-12]. Hence, even non-severe COVID-19 may pose a considerable hazard for global health and the international economy.

Although numerous studies have already addressed the differences between pathological profiles of severe and mild-to-moderate COVID-19, longitudinal trajectories within the circulating immune landscapes are still obscure [13,14]. However, a rapid identification of distinct disease stages might in the future allow for refined strategies with immunomodulatory therapies that support the host's immune response. These therapies may indeed gain importance as more and more variants may emerge that-despite efficient vaccination strategies-require the containment of viral loads after infection.

In order to rule out any bias from immunosuppressive therapy in severe COVID-19, we chose to concentrate on mild-to-moderate cases and to analyze the peripheral blood immune cell composition and its activation, plasma levels of cytokines, and SARS-CoV2 specific immunoglobulins. We then examined the complementary data sets for transient alterations in consecutive samples, indicative for differently progressed disease. Finally, we suggested distinct disease phases and characterized their immunological and serological layout.

\section{Materials and Methods}

\subsection{Study Population}

COVID-19 patients were recruited either from the local COVID-19 test center or from the division of tropical medicine and infectious diseases. After an initial withdrawal of peripheral blood on the day of testing or admittance to the hospital (day one), subsequent venipunctures followed on days three and seven. Individuals recruited at the test center who were tested negative were considered healthy controls and they were required to provide blood only once on the day of testing. Apart from sex and age, no other clinical parameters like co-morbidities or underlying conditions were documented for COVID-19 patients and healthy controls, respectively. The study was approved by the ethics committee of the University Medical Center of Rostock. It is filed under A 2020-0086 and written informed consent was obtained from all participants.

\subsection{Flow Cytometry}

For the analysis of surface expression markers, $100 \mu \mathrm{L}$ of anticoagulated COVID19 patient or healthy donor blood was used. In order to reduce unspecific antibodyconjugate binding, $10 \mu \mathrm{L}$ fetal calf serum (Thermo Fisher, Waltham, MA, USA), $5 \mu \mathrm{L}$ True-Stain Monocyte BlockerTM and $5 \mu \mathrm{L}$ anti-Fc receptor TruStain FcXTM (Biolegend, San Diego, CA, USA) were added and incubated for $15 \mathrm{~min}$ on ice. The following amounts of antibody:fluorophore-combinations were used: $0.25 \mu \mathrm{g}$ CD127:APC/R700 (clone HIL-7R-M21), $1 \mu \mathrm{g}$ CD147:BV421 (TRA-1-85), $0.5 \mu \mathrm{g}$ CD45RO:BV480 (UCHL1, BD Biosciences, Franklin Lakes, NJ, USA), $1 \mu \mathrm{g}$ CD11b:PerCP/Cy5.5 (ICRF44), $0.8 \mu \mathrm{g}$ CD11c:BV785 (3.9), $0.56 \mu \mathrm{g}$ CD14:BV510 (63D3), $0.13 \mu \mathrm{g}$ CD16:BV650 (3G8), $0.06 \mu \mathrm{g}$ CD19:APC /Fire810 (HIB19), 0.13 CD20:SparkNIR685 (2H7), 0.5 g CD27:BV605 (O323), $0.25 \mu \mathrm{g}$ CD3:SparkBlue550 (SK7), $0.25 \mu \mathrm{g}$ CD304:AlexFluor647 (12C2), $0.03 \mu \mathrm{g}$ CD4:BV750 (SK3), $0.5 \mu \mathrm{g}$ CD45RA:APC/Fire750 (HI100), $0.13 \mu \mathrm{g}$ CD56:BV711 (5.1.H11), $0.13 \mu \mathrm{g}$ CD8:BV570 (RPA-T8), $0.5 \mu \mathrm{g}$ CD95:PE/Cy5 (DX2), 0.13 IgD:PE/Dazzle594 (IA6-2), $0.13 \mu \mathrm{g}$ PD-1:APC (A17188B, Biolegend), $0.06 \mu \mathrm{g}$ CD38:PerCP/eFluor710 (HB7, Thermo Fisher), $0.06 \mu \mathrm{g}$ CD177:PE/Vio770 (REA258), $0.05 \mu \mathrm{g}$ CD25:PE (REA570, Miltenyi, Bergisch Gladbach, Germany). 
Antibodies were incubated for $45 \mathrm{~min}$ on ice in the dark. In parallel, in order to analyse the proportions of apoptotic leukocytes, Apotracker Green (Biolegend) was added directly to the blood samples according to the manufacturer's instruction with an incubation for $30 \mathrm{~min}$ on ice in the dark. In order to lyse erythrocytes, $2.2 \mathrm{~mL}$ Fixative-Free Lysing Solution (Thermo Fisher) was added and incubated for $20 \mathrm{~min}$ at room temperature in the dark. Following this, $0.03 \mu \mathrm{g} \mathrm{4}$, 6-diamidino-2-phenylindole was added as a live/dead discriminator and incubated for $5 \mathrm{~min}$. Finally, data acquisition was performed on the Cytek Aurora flow cytometer running on the SpectroFlo Software version 2.2.0.3 (Cytek Biosciences, Fremont, CA, USA). Analysis of flow cytometry data was done using the FlowJo software version 10.7 (FlowJo, Ashland, OR, USA) with the manual gating strategy shown in Figure S1. Dimension reduction of down-sampled and concatenated data sets was performed using the FlowJo plugin for the algorithm "uniform manifold approximation and projection" (UMAP) [15].

\subsection{Multipathway Posphoprotein Analyses}

T lymphocytes were obtained by processing $2 \mathrm{~mL}$ anticoagulated whole blood using CD3 MicroBeads on an automated magnetic activated cell sorting device (autoMACS, Miltenyi) according to the manufacturer's instructions. The fraction enriched for $\mathrm{CD}^{+}$cells was centrifuged and washed with $\mathrm{PBS}$ and frozen at $-80^{\circ} \mathrm{C}$. Cells from the $\mathrm{CD} 3^{-}$fraction were washed with Running Buffer (RB, Miltenyi) and erythrocytes were lysed by adding $5 \mathrm{~mL}$ Fixative-Free Lysing Solution (Thermo Fisher), mixing and incubating for $15 \mathrm{~min}$ at room temperature. The lysis was quenched by adding $10 \mathrm{~mL} \mathrm{RB}$ and mixing. Subsequently, cells were pelleted, suspended in RB and B lymphocytes were isolated by utilizing CD19 MicroBeads (Miltenyi) on an autoMACS. The fraction enriched for B lymphocytes was then washed and the cell pellet was frozen thereafter as described above. For the isolation of monocytes we used $2 \mathrm{~mL}$ anticoagulated blood and CD14 MicroBeads (Miltenyi). The $\mathrm{CD} 14^{+}$fraction was processed as mentioned above. The $\mathrm{CD} 14^{-}$fraction was submitted to the isolation of granulocytes by CD11b MicroBeads (Miltenyi) similar to the enrichment of CD19+ cells.

Proteins were obtained from sorted $\mathrm{CD}^{+}, \mathrm{CD}^{+} 9^{+}, \mathrm{CD} 14^{+}$and $\mathrm{CD} 1 \mathrm{~b}^{+}$cells by adding $40 \mu$ L MILLIPLEX Map Lysis Buffer containing 100-fold diluted Protease Inhibitor Cocktail Set III (Merck, Darmstadt, Germany) and mixing at $4{ }^{\circ} \mathrm{C}$ and $700 \mathrm{rpm}$ for at least $15 \mathrm{~min}$. Samples were subsequently centrifuged at $10,000 \times g$ for $10 \mathrm{~min}$ at $4{ }^{\circ} \mathrm{C}$. Supernatants were diluted fourfold and bulk protein concentrations were determined by using the Pierce BCA Protein Assay Kit (Thermo Fisher) following the manufacturer's guidelines. The absorbance was measured at $562 \mathrm{~nm}$ on the Infinite 200 automated plate reader (Tecan, Männedorf, Switzerland). Subsequently, samples were processed using the MILLIPLEX Multi-Pathway Cell Signaling Assay kits (Merck) for the semiquantitative analysis of either phosphorylated or unphosphorylated cAMP response element-binding protein (CREB), extracellular signalregulated kinases (ERK)1/2, nuclear factor kappa-light-chain-enhancer of activated B cells (NF-kB), c-Jun N-terminal kinase (JNK), p38, p70S6 kinase, signal transducer and activator of transcription (STAT) 3 and STAT5 to the manufacturer's instructions. In brief, 1-25 $\mu \mathrm{g}$ of total protein was used. Samples where protein concentrations were insufficient were excluded from further analysis. For calibration purposes, unstimulated and stimulated cell lyophilisates were reconstituted to a protein concentration of $2 \mathrm{mg} / \mathrm{mL}$. In detail, the kit provided unstimulated HeLa cells, HeLa cells stimulated with tumor necrosis factor (TNF) $\alpha /$ Calyculin A, MCF7 cells stimulated with insulin-like growth factor 1 and A431 cells stimulated with epidermal growth factor. Serial dilutions were performed and processed in parallel to the samples. Data acquisition was performed on the Luminex 100/200 flow cytometer with the acquisition software xPONENT version 3.1.871.0 (Luminex, Austin, TX, USA).

Data analysis was performed by log10-transformation of raw median fluorescence intensity (MFI) values and annotating arbitrary units (AUs) for the respective standard dilution. In order to obtain AUs for samples, we utilized a linear regression model for the 
calibration standards onto which transformed sample MFI values were fitted. After backtransformation, the data for unphosphorylated proteins were normalized to the amount of whole protein from the BCA assay. AUs for phosphorylated proteins were normalized to AUs from their unphosphorylated counterparts. For heatmap visualization, the data was normalized to a $0-1$ range ( $\mathrm{z}$ value).

\subsection{SARS-CoV-2 Specific Antibodies}

Plasma samples were obtained by centrifugation of anticoagulated blood from healthy donors and COVID-19 patients, respectively. For the semi-quantitative analyses of IgM and IgG specific for the nucleocapsid $(\mathrm{N})$ or the spike protein subunits S1, S2 and receptor binding domain (RBD), we used the respective MILLIPLEX SARS-CoV-2 antigen panel kits (Merck) to the manufacturer's instructions. In brief, plasma samples were diluted 100 -fold in assay buffer and were incubated with antigen-conjugated beads for $2 \mathrm{~h}$ at room temperature with shaking at $600 \mathrm{rpm}$. After washing, PE-conjugated anti-human IgG/IgM detection antibodies were added to the samples followed by incubation for $1.5 \mathrm{~h}$ at room temperature and $600 \mathrm{rpm}$. Samples were then washed, immersed in sheath fluid (Merck) and analyzed on the Luminex 100/200 flow cytometer (Luminex). For the detection of trimeric spike protein specific IgA we used an enzyme-linked immunosorbent assay according to the manufacturer's specifications (Euroimmun, Lübeck, Germany). Absorbances were detected at $450 \mathrm{~nm}\left(\mathrm{~A}_{450}\right)$ on the Infinite 200 automated plate reader (Tecan).

\subsection{Cytokine Analysis}

For the determination of cytokine concentrations in plasma samples, the LEGENDplex Human Anti-Virus Response Panel (Biolegend) was used containing capture beads and detection antibodies for Interleukin (IL-)1 $\beta$, IL-6, IL-8, IL-10, IL-12p70, Interferon (IFN) $\alpha$, IFN $\beta$, IFN $\lambda 1$, IL-29, IFN $\lambda 2 / 3$, IL-28, IFN $\gamma, \mathrm{TNF} \alpha$, interferon gamma-induced protein 10/C-X-C motif chemokine ligand 10 (IP10/CXCL10) and granulocyte-macrophage colony-stimulating factor (GM-CSF). The protocol was followed using the manufacturer's instructions. Data acquisition was performed using the Cytek Aurora (Cytek Biosciences).

\subsection{Statistics}

Data analysis and visualization were performed using R (version 3.5.1), InStat (GraphPad, San Diego, CA, USA) and SPSS (IBM, Armonk, NY, USA). Contingency tables were compared by the Fisher's exact test. Normality of data sets was evaluated using the Kolmogorov-Smirnov test. Comparisons for multiple groups were done by analysis of variance (ANOVA) under the assumption for normally distributed sample data. Pairwise comparisons were conducted post-hoc with the Tukey-Kramer test. Non-normally distributed data were compared by the Kruskal-Wallis one-way analysis of variance with post-hoc pairwise comparisons using the Mann-Whitney-Wilcoxon (MWW) test and adjustment of $p$-values with the Holm-Bonferroni method. The Spearman rank method was used for correlation analyses. A $p$-value of $<0.05$ was considered statistically significant.

\section{Results}

\subsection{Mild-to-Moderate COVID-19 Induces Minor Changes in Immune Cell Subpopulation Distribution and Activation}

Twenty-eight participants were recruited from the local COVID-19 test center. Reasons for visiting were either return from high incidence regions, direct contact with SARS-CoV-2 infected individuals or experience of COVID-19 related symptoms, respectively. Eight of these participants tested positive for SARS-CoV-2 but did not require hospitalization due to mild symptoms. Fourteen inpatients were recruited from the division of tropical medicine and infectious diseases. All of them ran non-severe disease courses without the need for intensive care. Among all participants, two patients were available for three consecutive venipunctures, nine for two and eleven for a single one. Table 1 lists the demographic data 
of patients and healthy donors showing an even distribution of sex and comparable age ranges.

Table 1. Demographics of patients and controls.

\begin{tabular}{cccc}
\hline & Controls $(\boldsymbol{n}=\mathbf{1 9 )}$ & COVID-19 Patients $(\boldsymbol{n = 2 2 )}$ & $\boldsymbol{p}$-Value \\
\hline sex (male/female) & $9 / 10$ & $11 / 11$ & $1^{*}$ \\
median age (min-max) & $68(22-89)$ & $57(22-85)$ & $0.574^{\#}$ \\
\hline * resulting from Fisher's exact test ${ }^{*}$ r resulting from Mann-Whitney Wilcoxon test.
\end{tabular}

* resulting from Fisher's exact test, ${ }^{*}$ resulting from Mann-Whitney Wilcoxon test.

In order to further our understanding of early immune cell responses in the peripheral blood during mild-to-moderate COVID-19, we performed 24-dimensional flow cytometry analyses and in a first approach compared healthy controls with SARS-CoV-2 infected patients from all time points. Our primary goal was to define whether subpopulations of neutrophilic granulocytes, monocytes and lymphocytes of the $\mathrm{B}$ or $\mathrm{T}$ lineage were specifically enriched during early infection. For that, we performed dimension reductions on our multiparametric data sets by using the embedding algorithm UMAP. Figure $1 \mathrm{~A}$ shows the topological distributions of immune cell subpopulations based on different surface antigen expression patterns for healthy controls and COVID-19 patients, respectively. While the data imply ample variation for the abundance of $\mathrm{CD} 19^{+}$and $\mathrm{CD} 177^{+}$populations between both groups, the differences regarding $\mathrm{CD}^{+}$and $\mathrm{CD} 14^{+}$populations were less prominent.

A

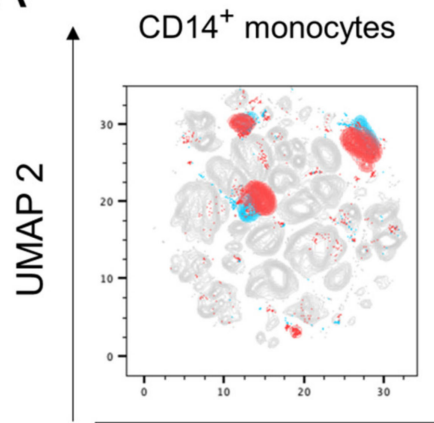

$\mathrm{CD}_{177^{+}}$granulocytes

$\mathrm{CD}^{+} \mathrm{T}$ cells

CD19+ ${ }^{+}$cells
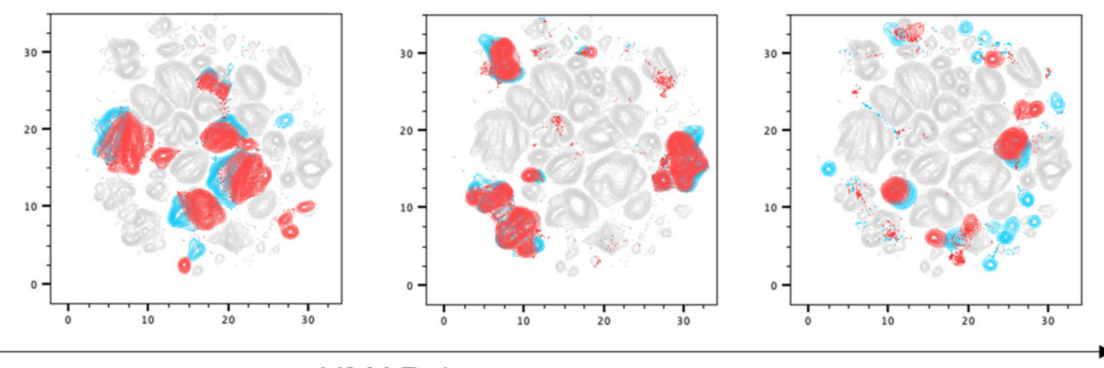

UMAP 1

B

$\mathrm{CD}_{14}^{+}$monocytes

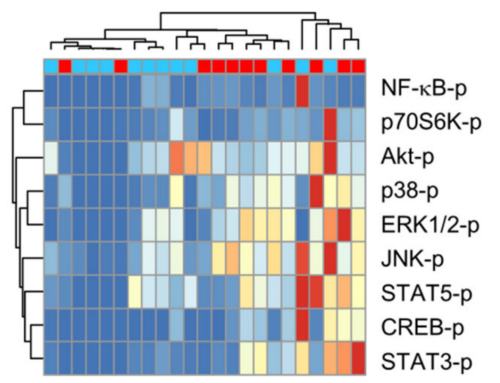

\section{CD $19^{+}$B cells}

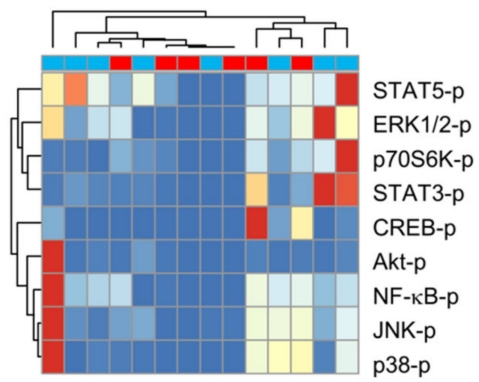

Figure 1. Multidimensional flow cytometry and phosphoprotein analyses revealed minor changes of bulk immune cell response during mild-to-moderate COVID-19. (A) UMAP projection of flow cytometry data show the topological distribution of immune cell populations based on differentially expressed surface antigen patterns between healthy controls and COVID-19 patients. (B) Heatmaps of normalized protein phosphorylation data from sorted CD14+ monocytes (left) and CD19+ B lymphocytes (right) demonstrated contingent hierarchical clustering of healthy controls and COVID19 patients. 
We next sought to investigate whether SARS-CoV-2 infection induced the activation of particular signaling pathways in immune cells. For that, we sorted $\mathrm{CD}^{+}, \mathrm{CD} 11 \mathrm{~b}^{+}$, $\mathrm{CD}_{14}{ }^{+}$and $\mathrm{CD} 19^{+}$cells from peripheral blood samples and analyzed from lysates the extent of protein phosphorylation. Figure $1 \mathrm{~B}$ exemplifies for $\mathrm{CD} 14^{+}$monocytes a hierarchical clustering that suggests increases of phosphorylated p38, ERK1/2, JNK, STAT3, STAT5 and CREB in COVID-19 patients. However, when analyzing individual signaling pathways in more detail, variances among groups turned out to be very high and obscured potential differences between patients and controls (Table S1). Likewise, cluster analyses of phosphorylated signaling molecules in $\mathrm{CD}^{+}{ }^{+}, \mathrm{CD}^{+}$or $\mathrm{CD} 11 \mathrm{~b}^{+}$cells did not reveal any COVID-19 specific activation of the respective pathways (Figure 1B, Tables S2-S4).

Our broad survey of surface expression- and intracellular activation data therefore hint at rather small-scale alterations among bulk immune cell responses during mild COVID-19 and hence call for a more sophisticated data-dependent stratification.

\subsection{The Fraction of Plasmablasts in Combination with Antibody Titers Delineate Infection Phases}

In order to explain the variation among the COVID-19 samples, we aimed to delineate a time line of early immune events following SARS-CoV-2 infection. However, neither the date of a positive test result for SARS-CoV-2 nor hospital admission are suitable reference points for the classification of different disease phases, as COVID-19 leads to a diverse collection of symptoms that may be delayed or may fail to develop altogether even in the presence of substantial viral loads [16-18]. We therefore reviewed our multidimensional flow cytometry data for advanced clues that would allow for the assignment of the various samples to specific disease stages along this timeline and for subsequent comparison of these disease stages with each other and to the controls.

As was recently described for COVID-19, enrichment of a distinct population of the $B$ lineage cells may indicate a shift from the steady state immune constitution and point towards an early adaptive response [19-21]. Indeed, we found a transient increase of $\mathrm{CD} 9^{+} \mathrm{CD} 45 \mathrm{RA}^{+} \mathrm{CD} 27^{+} \mathrm{CD} 38^{\text {bright }}$ plasmablasts in consecutive samples from COVID-19 patients (Figure 2A).

Accordingly, dynamics of early antibody producing cells and class-switching may translate into a time- or disease stage-dependent accumulation of immunoglobulins (Igs) of different isotypes. A very early stage post infection should be devoid of any antibodies and, thereafter, IgM, IgA and IgG specific for viral proteins may appear almost simultaneously. In fact, it has been shown that IgM titers will increase for about two weeks after emergence before they plateau, while amounts of IgA and IgG are expected to increase over a longer period of time [21,22].

Given these assumptions, we analyzed SARS-CoV-2 specific Igs in plasma samples and integrated the dynamics of peripheral $\mathrm{IgD}^{-}$plasmablasts in order to stratify our data set. We thus were able to define four different disease stages: (i) healthy controls that have no antibodies against SARS-CoV-2 and feature a mean of $1.1 \pm 0.2 \%$ of plasmablasts among $\mathrm{CD} 19^{+} \mathrm{CD} 45 \mathrm{RA}^{+}$lymphocytes, (ii) an incubation phase with still negligible SARS-CoV-2 specific Igs and a mean of $2.9 \pm 0.8 \%$ of plasmablasts, (iii) early acute infection characterized by elevated $\operatorname{IgM}, \operatorname{IgG}$ and IgA titers along with a significantly increased proportion of plasmablasts $(11.5 \pm 2.6 \%)$, and (iv) a late acute infection phase defined by a reduction in plasmablasts $(4.4 \pm 1.1 \%)$ together with stable IgM and minor increases in IgA and IgG titres (Figure 2B, Tables S5 and S6). Of note, we assumed that age would be a confounding variable influencing some of our data and therefore incorporated analyses of covariants (ANCOVA) in order to eliminate age from the statistical model (Figure 2B and Table S5). Indeed, we found that age specifically operated on the null hypothesis rejection for the alteration of $\mathrm{CD} 27^{+} \mathrm{CD} 38^{\mathrm{dim}}$ early memory B-lymphocytes which were nonetheless altered between different disease stages when precluding the confounding covariable (Table S5).

In summary, our data demonstrated that utilizing the dynamics of both plasmablast trajectories and SARS-CoV-2 specific Ig titers allowed for the delineation of patient data into differently progressed disease phases. 
A
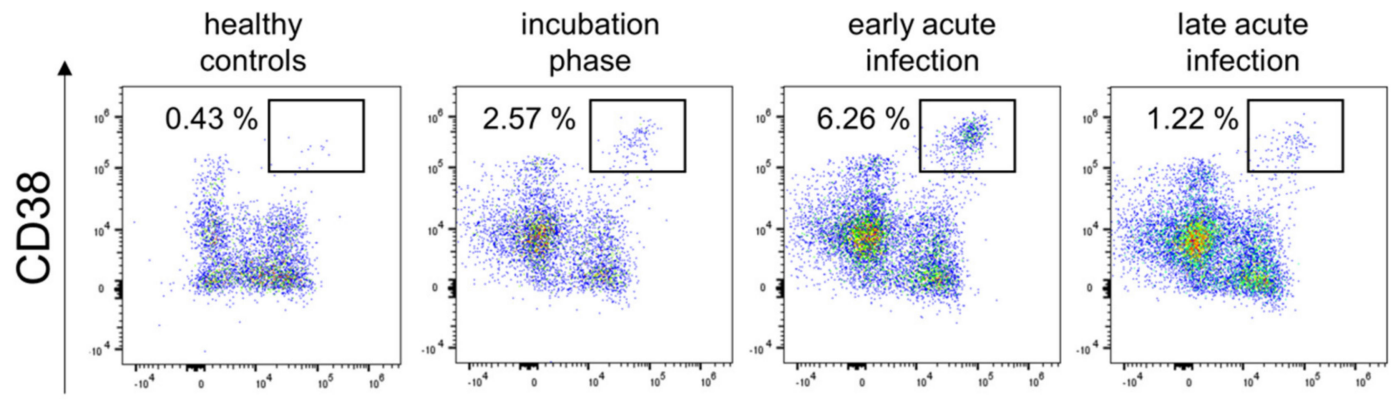

B

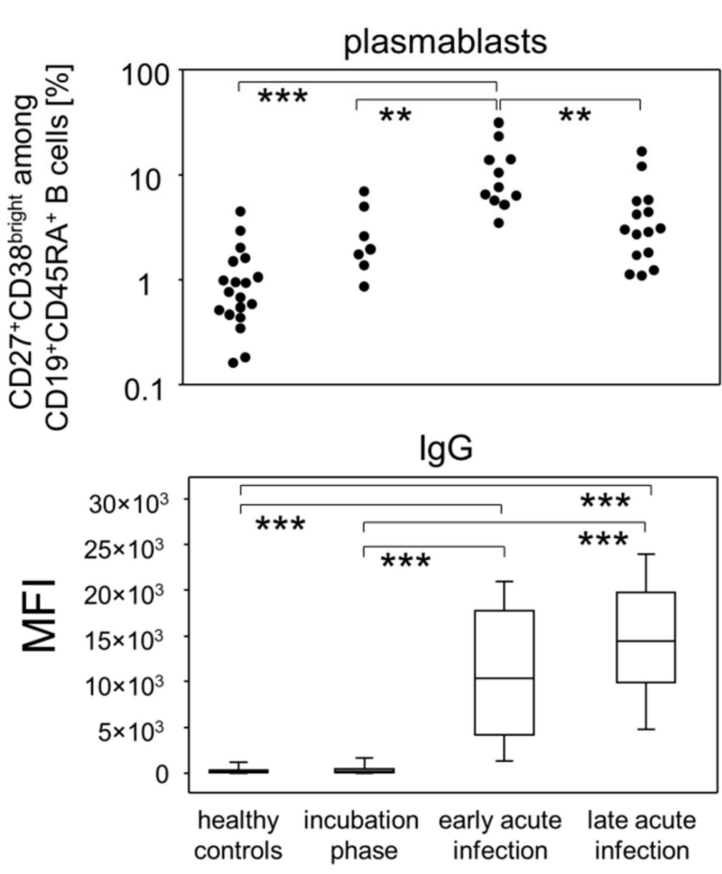

CD27
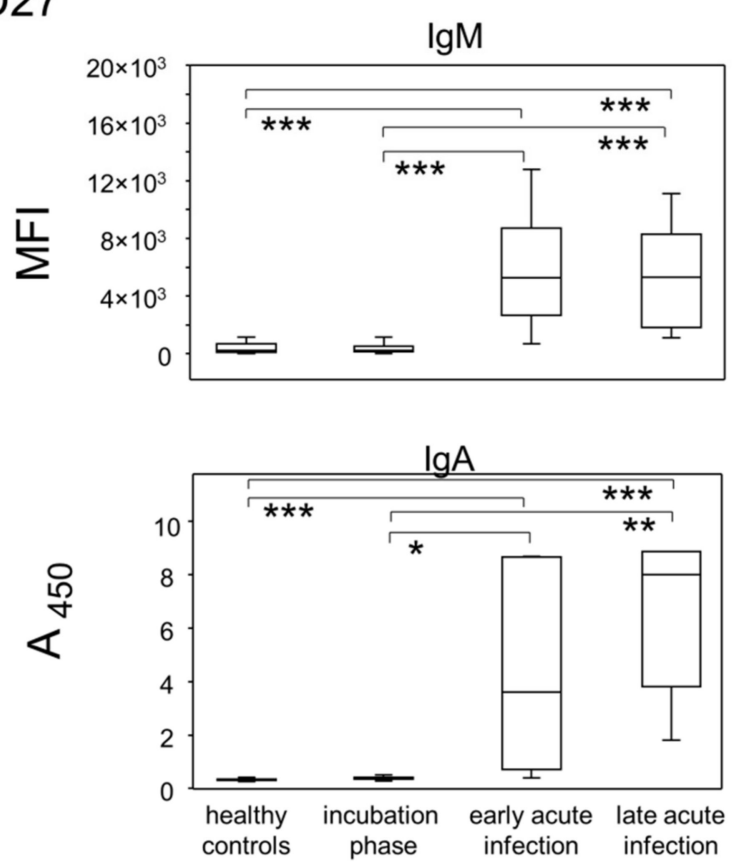

Figure 2. Kinetics of plasmablast proportions and SARS-CoV-2 specific immunoglobulin enrichment delineated disease stages during mild-to-moderate COVID-19. (A) Representative pseudocolor plots of CD38 and CD27 expression data of CD19+CD45RA ${ }^{+}$B lymphocytes showed the disease stage-dependent increase of plasmablast proportions (rectangular gate). (B) Top left: Quantitative data of plasmablast abundances at different disease stage. Top right, bottom left and bottom right: Semi-quantitative data of SARS-CoV-2 specific IgM, IgG and IgA titers in plasma samples. The data for anti-RBD, -S1, -S2 and -N were combined for IgM and IgG, respectively. ${ }^{*} p<0.05 ;{ }^{* *} p<0.01$; *** $p<0.001$; Tukey-Kramer test for plasmablasts, Kruskal-Wallis test with Dunn's correction for multiple comparisons for Antibody isotypes. MFI: Median fluorescence intensity. $\mathrm{A}_{450}$ : Absorbance at $450 \mathrm{~nm}$.

\subsection{Pro-Inflammatory Monocytes and $\mathrm{CD}^{-} \mathrm{CD}^{-} \mathrm{CD} 7^{+}$Granulocytes Follow Different Kinetics during Mild-to-Moderate COVID-19}

Building on the fact that early phases of viral infection trigger innate immune responses, we sought to investigate the dynamics of monocyte and granulocyte subpopulations between the above postulated disease phases. Peripheral monocytes were defined via sideward scatter and expression of CD14. The additional analysis of CD16 expression allowed for the differentiation of classical $\left(\mathrm{CD} 14^{+} \mathrm{CD} 16^{-}\right)$, anti-viral $\left(\mathrm{CD} 14^{+} \mathrm{CD} 16^{+}\right)$and pro-inflammatory monocytes $\left(\mathrm{CD} 14^{+} \mathrm{CD} 16^{\text {bright }}\right)$. Figure 3 demonstrates for the contingent of pro-inflammatory monocytes a moderate but statistically not quite significant increase in the incubation phase when compared to healthy controls $(p=0.0766)$. However, upon progression into the acute infection phases, this population of monocytes was significantly 
reduced (Figure 3). Finally, we did not find any meaningful differences between the remaining monocyte subpopulations and the various phases of the disease (Table S7).

A

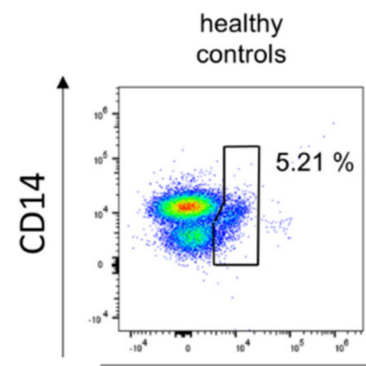

incubation

phase

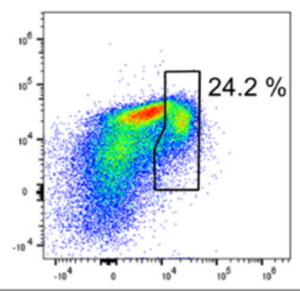

early acute infection

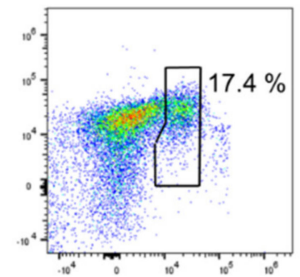

CD16

B

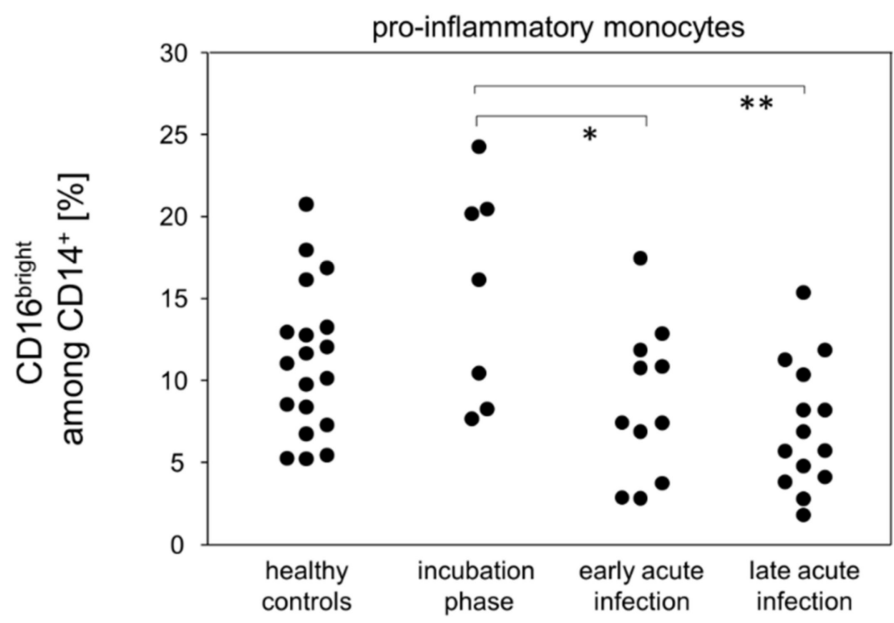

Figure 3. Pro-inflammatory monocytes were more abundant during the incubation phase. (A) Representative pseudocolor plots of CD14 and CD16 expression data of SSC ${ }^{\text {med }}$ monocytes demonstrated kinetics for the enrichment of pro-inflammatory monocytes (polygonal gate). (B) Quantitative data of pro-inflammatory monocyte proportions. ${ }^{*} p<0.05$; ${ }^{* *} p<0.01$; Tukey-Kramer test.

For granulocytes we gated SSChi cells and then differentiated subpopulations by their expression patterns for CD11b, CD16 and CD177. While most of the granulocyte subpopulations were unaltered between all disease stages, we found that $\mathrm{CD} 16^{-} \mathrm{CD} 177^{+}$cells were slightly increased during the incubation phase and early acute infection. However, during late acute infection, there was a significant increase in this population compared to healthy controls (Figure 4 and Table S8).

In summary, the definition of early disease phases allowed for the detection of different kinetics among innate immune cells. While the proportion of pro-inflammatory monocytes increased rather early in the response to SARS-CoV2, $\mathrm{CD} 16^{-} \mathrm{CD} 177^{+}$granulocytes were found to accumulate in the late acute infection stage. 
A

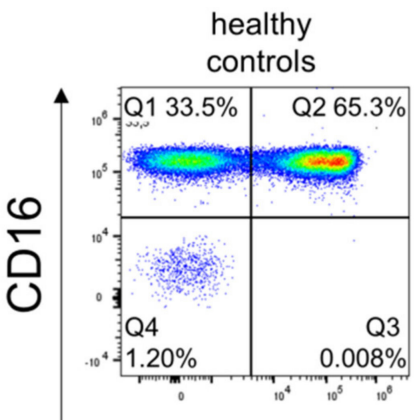

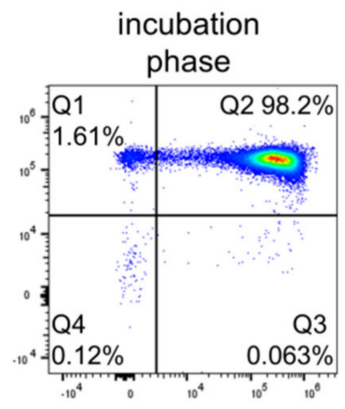
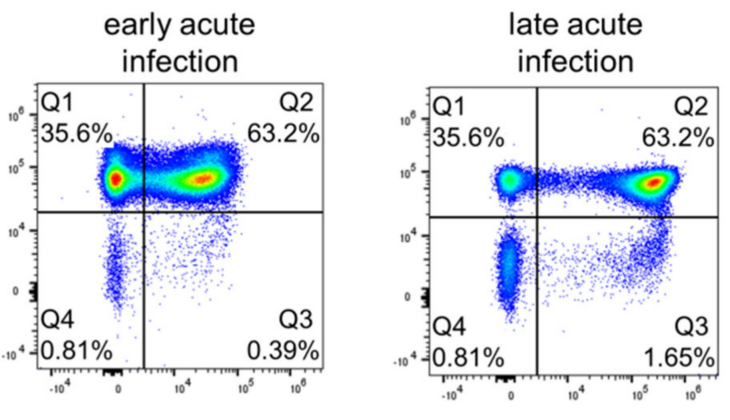

CD177

B

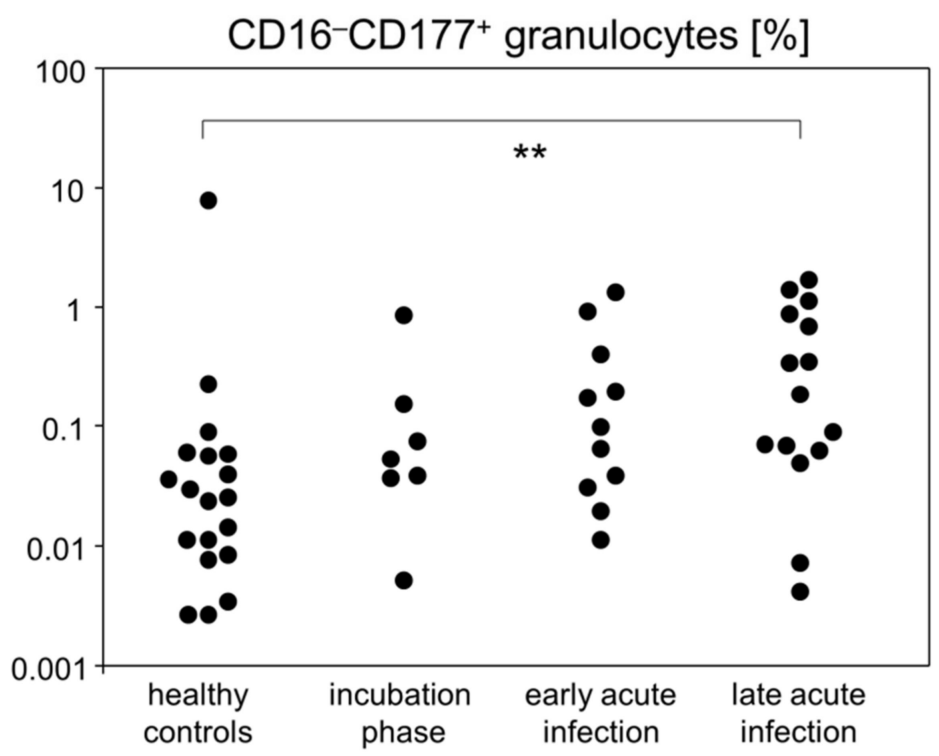

Figure 4. The portion of $\mathrm{CD} 16^{-} \mathrm{CD} 177^{+}$granulocytes gradually increased until the late acute infection phase. (A) Representative pseudocolor plots of CD16 and CD177 expression data of SSChi leukocytes showed that $\mathrm{CD} 16^{-} \mathrm{CD} 177^{+}$granulocytes specifically emerged at the late acute infection phase (Q3 gate). (B) Quantitative flow cytometry data indicated gradually increasing abundances of $\mathrm{CD}_{16}{ }^{-} \mathrm{CD} 177^{+}$granulocytes. ${ }^{* *} p<0.01$; Tukey-Kramer test.

3.4. Incubation and Early Acute Infection Phases Are Characterized by an Increase in Activated Cytotoxic T Cells and IP-10

In order to characterize in detail the cytotoxic $\mathrm{T}$ cell response during incubation as well as early and late acute infection phases, $\mathrm{CD} 8^{+}$cells were analyzed for their activation (CD25, CD38), exhaustion (PD-1) and differentiation status (CD45RA, CD27, CD127). While the fraction of naïve $\left(\mathrm{CD} 45 \mathrm{RA}^{+} \mathrm{CD} 27^{+}\right) \mathrm{CD} 8$-positive $\mathrm{T}$ cells was strictly age dependent, there were no further associations with any of the disease phases. However, the incubation phase was characterized by a significant relative increase in $\mathrm{CD}_{4} 5 \mathrm{RA}^{+} \mathrm{CD} 38^{+} \mathrm{CD} 27^{-}$cytotoxic T cells (Figure 5A), indicating an activated and terminally differentiated status [23]. This fraction of $\mathrm{CD} 38^{+} \mathrm{CD} 27^{-}$cytotoxic T cells gradually declined over the different phases of acute infection (Figure 5A,B). Following a different kinetic, CD45RA ${ }^{+} \mathrm{CD} 38^{+} \mathrm{CD} 27^{+}$cytotoxic T cells, suggestive of TSCM (stem cell memory) started to increase during incubation yet reached a significant difference compared to healthy controls only during late acute infection (Figure 5A and Table S9). Likewise, CD45RA ${ }^{+} \mathrm{CD} 127^{-} \mathrm{CD} 27^{+}$cells, indicative of TEMRA (effector memory re-expressing RA), started to increase during early acute infection and were significantly elevated during late acute infection (Table S9). Moreover, all disease phases featured an elevated expression of CD38 on CD8 ${ }^{+}$cells (Figure 5C and Table S10). 
A

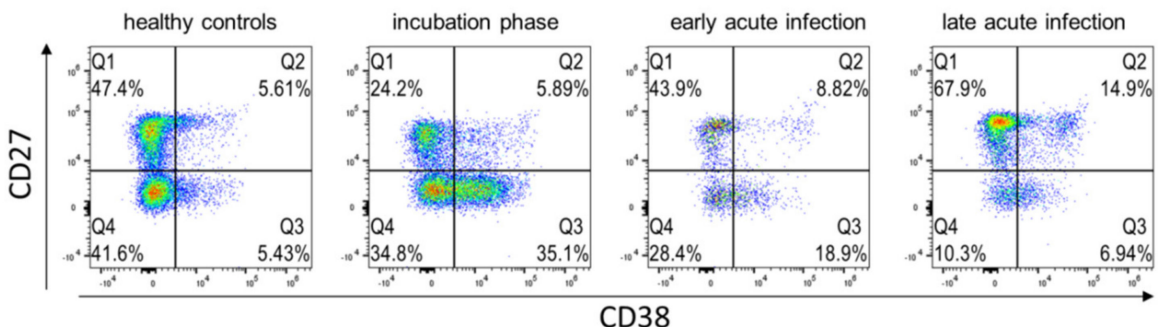

B

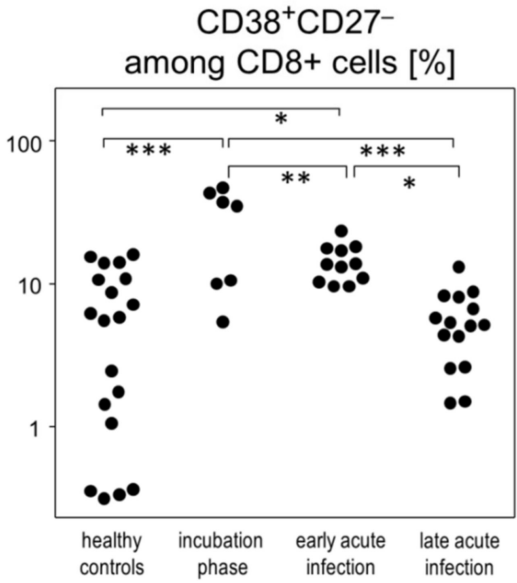

C
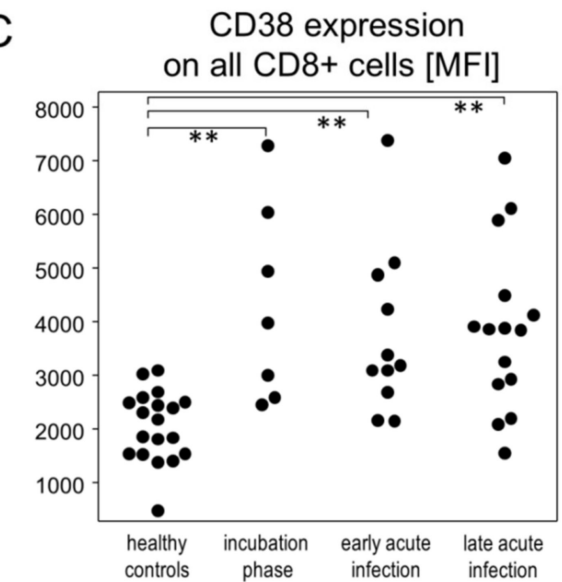

$\mathrm{D}$

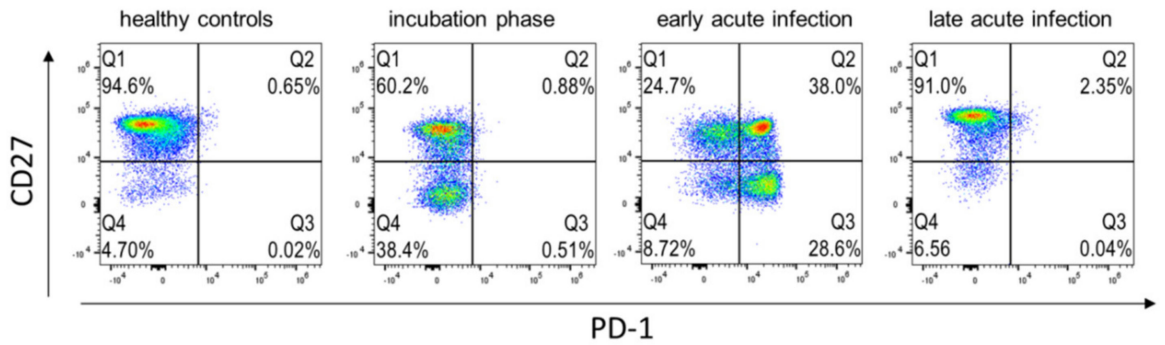

E

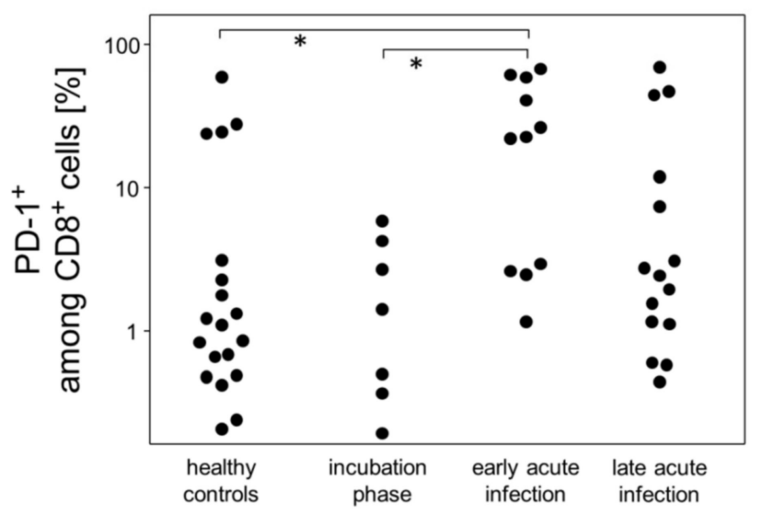

Figure 5. The scope of cytotoxic $\mathrm{T}$ lymphocytes activation depended on the respective disease stage during mild-to-moderate COVID-19. (A) Representative pseudocolor plots of CD38 and CD27 expression data of $\mathrm{CD} 8^{+} \mathrm{T}$ cells demonstrated the accumulation of the $\mathrm{CD} 38^{+} \mathrm{CD} 27^{-}$subpopulation (Q3 gate) during the incubation and early acute infection phases. (B) Quantitative flow cytometry data of $\mathrm{CD} 88^{+} \mathrm{CD} 38^{+} \mathrm{CD} 27^{-} \mathrm{T}$ cell proportions. (C) $\mathrm{CD} 38$ expression by $\mathrm{CD} 8^{+} \mathrm{T}$ cells at the different disease stages. (D) Representative plots of PD-1 and CD27 expression data showed an increase of PD-1 ${ }^{+} \mathrm{T}$ cells that are either $\mathrm{CD} 27^{+}$(Q2 gate) or $\mathrm{CD} 27^{-}$(Q3 gate). (E) Quantitative data of $\mathrm{CD} 8^{+} \mathrm{PD}-$ $1^{+} \mathrm{T}$ cell proportions showed their enrichment during the incubation and acute infection phases. ${ }^{*} p<0.05 ;{ }^{* *} p<0.01$; ${ }^{* * *} p<0.001$; Tukey-Kramer test. 
Finally, we observed a significantly increased fraction of PD- $1^{+}$cells among cytotoxic T cells during the early acute infection phase. These PD- $1^{+}$cells were either CD27 ${ }^{-}$or CD27 and already in the decline during late acute infection (Figure 5D,E and Table S9). In contrast to the alterations among $\mathrm{CD}^{+}$subpopulations, we did not observe similarly prominent changes among $\mathrm{CD} 4^{+} \mathrm{T}$ helper cell differentiation/activation stages and the various disease phases (Table S11). Neither were there significant changes among CD25+CD $127^{+}$regulatory T cells nor NK cells (Tables S11 and S12).

Finally, we investigated the kinetics of 13 cytokines in an anti-virus response panel and found that IP-10 (CXCL10) was transiently elevated during both the incubation phase and early acute infection before returning to baseline in late acute infection (Figure 6 and Table S13). In support of mild-to-moderate COVID-19 courses in our cohort, we did not detect a cytokine storm for any of the analytes measured. We did, however, find slight increases of IL-6, IL-8, IL-12, TNF $\alpha$, IFN $\gamma$, IFN $\alpha 2$, IFN $\lambda 1$, IFN $\beta$, GM-CSF and IL-10, mostly for the acute infection stages. However, none of these exhibited a meaningful effect size yet were subject to high variance (Table S13).

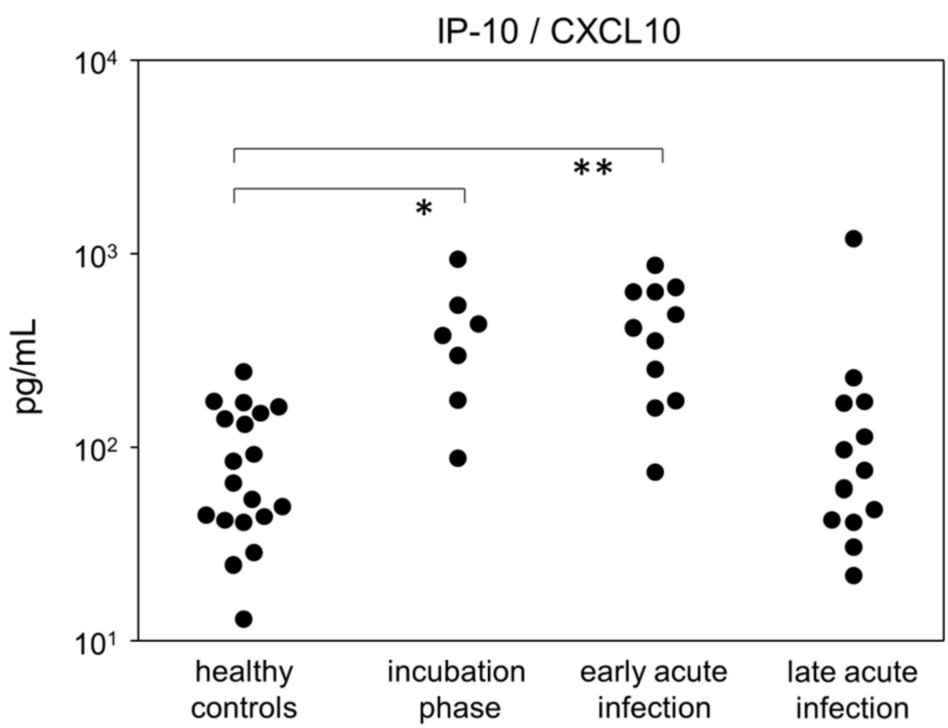

Figure 6. Quantitative data of IP-10 concentrations in plasma samples at different disease stages. ${ }^{*} p<0.05 ;{ }^{* *} p<0.01$; Tukey-Kramer test.

In summary, while the increase of activated $\mathrm{CD} 38^{+} \mathrm{CD} 27^{-}$and activated or exhausted PD- $1^{+}$cytotoxic $T$ cells was mostly restricted to the incubation phase and early acute infection, respectively, we found the activation marker CD38 to be overexpressed during all disease phases.

\subsection{Incubation and Early Acute Infection Are Characterized by T Lymphopenia Unrelated to Apoptosis}

In order to also assess quantitative differences among the major leukocyte populations during the early disease phases, we determined absolute numbers of live granulocytes, lymphocytes and monocytes. The picture emerging revealed lymphopenia during incubation and early acute infection which slowly recovered during late acute infection (Table S14). This lymphopenia was based on a decrease in T lymphocytes and affected both T helper cells and cytotoxic T cells (Figure 7A). Quantitative differences among B cell, granulocyte, and monocyte bulk populations did not reach statistical differences (Table S14). To rule out apoptosis as the reason for $\mathrm{T}$ lymphopenia, we calculated the respective proportions of apoptotic cells among live leukocytes. However, no significant variations emerged that paralleled the fluctuating numbers of live $\mathrm{T}$ cells nor were there any other populations affected (Figure 7B and Table S15). Apoptosis therefore could not be held responsible for the decrease of peripheral $\mathrm{T}$ lymphocytes during incubation and early acute infection. 
A

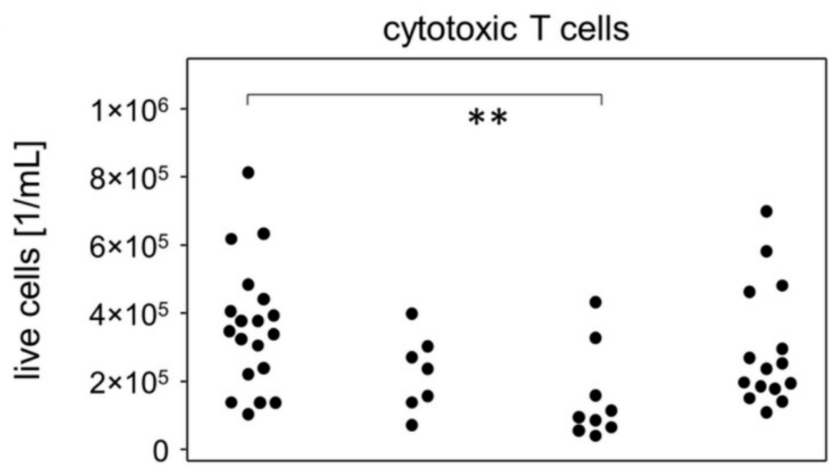

B

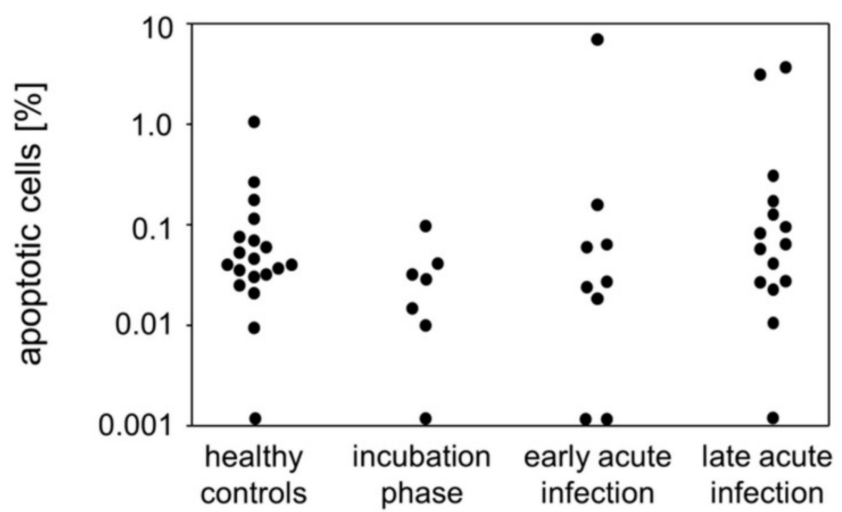

Thelper cells
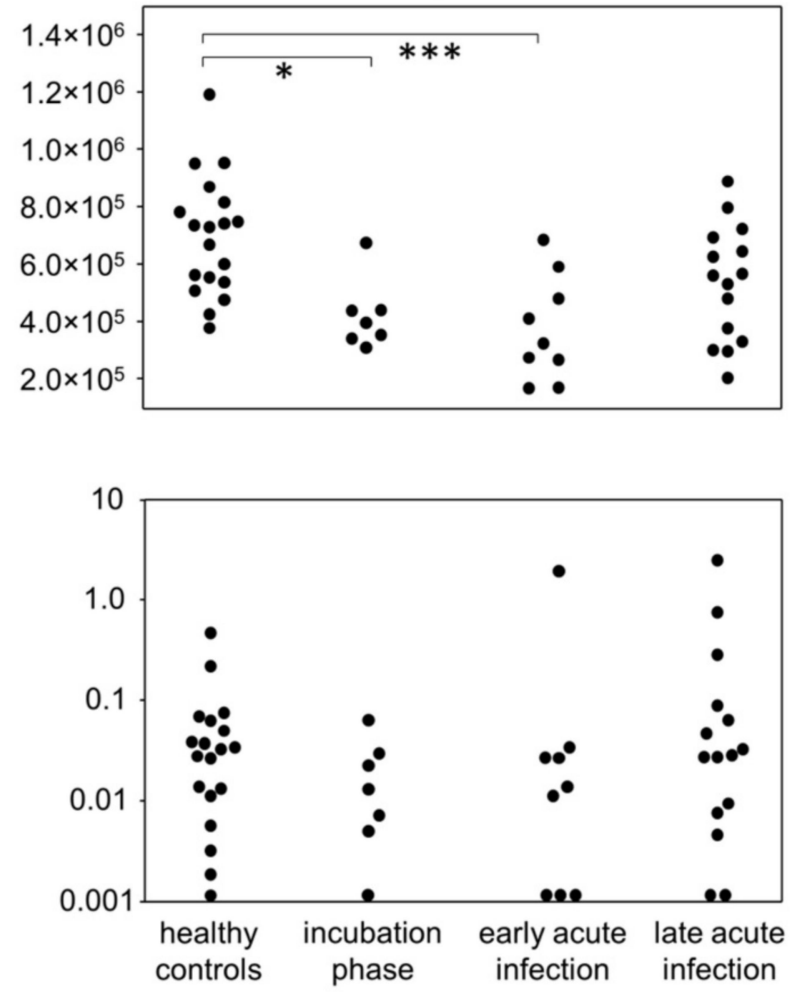

Figure 7. Mild-to-moderate COVID-19 induced apoptosis-independent $\mathrm{CD} 4^{+}$and $\mathrm{CD} 8^{+} \mathrm{T}$ lymphopenia at the incubation and early infection phases. (A) Total cell numbers of cytotoxic T cells (left) and T helper cells (right). (B) Quantitative data of apoptotic cell proportions among cytotoxic T cells (left) and T helper cells (right). ${ }^{*} p<0.05 ;{ }^{* *} p<0.01 ;{ }^{* * *} p<0.001$; Tukey-Kramer test.

\subsection{IP-10 in Patients Correlates with Different Immune Parameters Than in Healthy Controls}

Finally, we performed correlation analyses for all immune parameters assessed. As for the healthy controls, the only significant correlation existed between the fraction of proinflammatory monocytes (CD14 ${ }^{+} \mathrm{CD} 16^{\text {bright }}$ ) and serum concentrations of IP-10 (Table S16). In contrast, in the patients, serum IP-10 correlated significantly with $\mathrm{CD} 38^{+} \mathrm{CD} 27^{-}$terminally differentiated cytotoxic T cells (Table S17). Moreover, patient serum concentrations of all anti-S isotypes correlated significantly with each other and also with the fraction of immature neutrophilic granulocytes.

\section{Discussion}

By analyzing longitudinal trajectories of immune responses to SARS-CoV-2 in patients experiencing mild-to-moderate disease courses, we were able to define three different stages (Figure 8). The first one comprises the incubation phase, which for the patients manifested with symptoms that led to voluntary testing or-in the case of elderly or multimorbid patients-to hospitalization. The immune response in this phase of disease progression is characterized by significant increases in pro-inflammatory monocytes $\left(\mathrm{CD} 14^{+} \mathrm{CD} 16^{\text {bright }}\right)$, activated cytotoxic T cells $\left(\mathrm{CD} 38^{+}\right)$, and serum IP-10 paralleled by a significant decrease of peripheral $\mathrm{T}$ helper cell numbers. This incubation phase is followed by the early acute infection where peripheral plasmablasts $\left(\mathrm{CD} 27^{+} \mathrm{CD} 38^{\text {bright }}\right)$ are transiently yet significantly elevated, as are exhausted cytotoxic T cells $\left(\mathrm{PD}-1^{+}\right)$. IP-10 is still significantly upregulated, while both helper and cytotoxic $\mathrm{T}$ cells are significantly reduced. Virus-specific $\operatorname{IgM}, \operatorname{IgG}$ and IgA antibodies are detectable, and except for IgM, still on the rise. Finally, during late acute infection, most values appear to be returning to normal except for virus-specific 
antibodies and immature neutrophils which are now significantly elevated compared to the healthy controls (Figure 8).

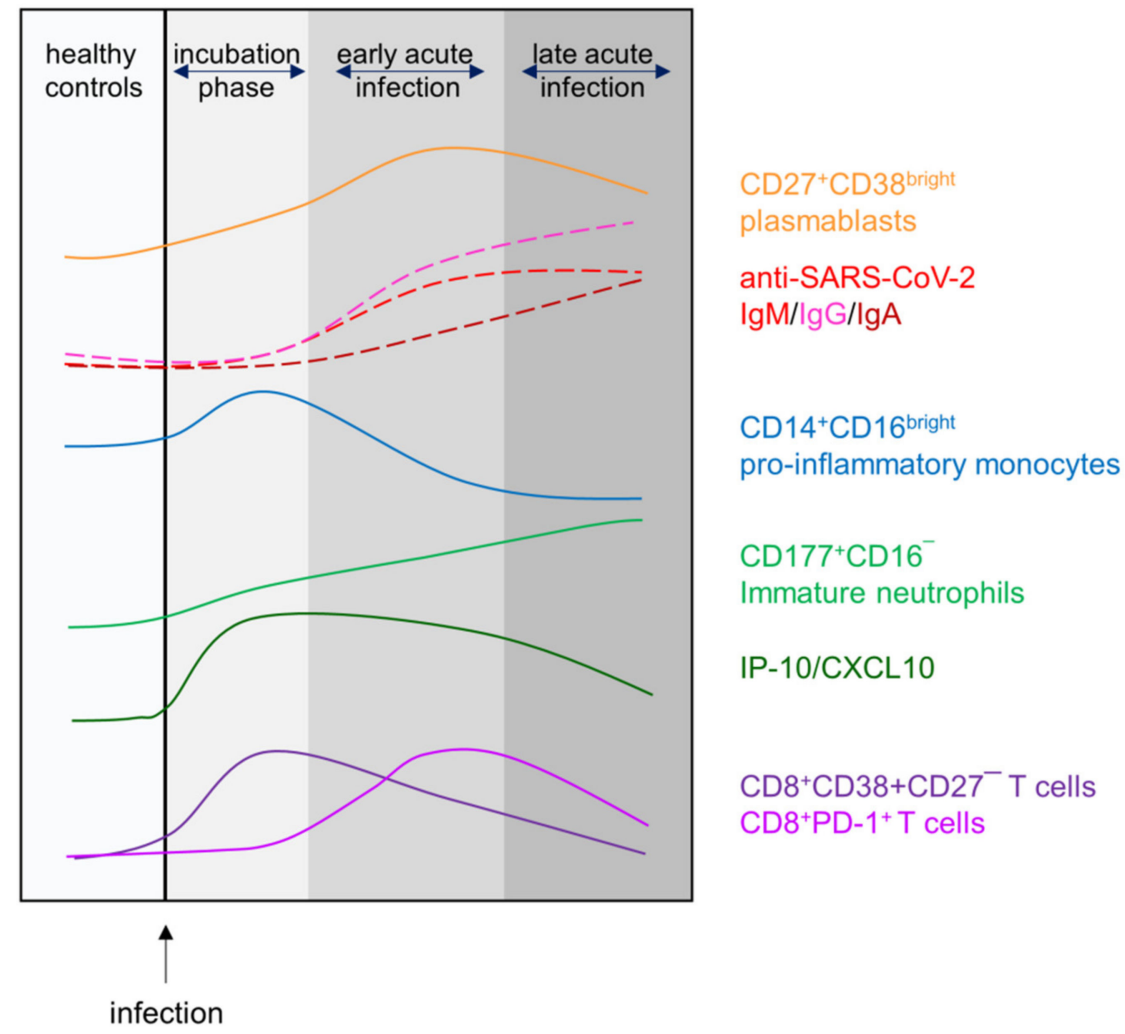

Figure 8. Differential kinetics of immune cell populations along distinct disease stages during mild-to-moderate COVID-19.

We here show that the transient increase in peripheral plasmablasts in combination with seroconversion and relative increases in Ig subclasses serve as reference points to time early phases of COVID-19. While plasmablasts increase between days one and nine after onset of symptoms and peak around day nine [22], SARS-CoV-2 specific antibodies can be detected as early as three to six days post onset of symptoms [20,21]. Importantly, Ig subclasses in the serum did not appear to follow the classical IgM-IgG-IgA sequence of events, as shown e.g., for the seroconversion following HIV infection [24,25]. Instead, whether IgM or IgG appeared first seemed to depend on the antigen with anti-N and anti-S2 inducing a robust IgG and anti-S1 and anti-RBD inducing an IgM response first. IgA appeared simultaneously with either IgM or IgG; however, while IgM on average plateaued during early acute infection, $\operatorname{IgG}$ and $\operatorname{IgA}$ were still on the rise during late acute infection. We here did not specifically assess SARS-CoV-2 neutralizing antibodies yet refer to a previous publication demonstrating that IgA dominates the early neutralizing response [22].

Taking the alteration of peripheral plasmablasts and virus-specific antibodies as a basis to define various phases of COVID-19 allowed for the detection of small scale alterations among bulk immune cell responses which otherwise were obscured. For example, we here show that the incubation phase is characterized by a sharp increase in pro-inflammatory monocytes and, indeed, this increase has previously been confirmed for both acute Dengue and HI virus infections [26,27]. During Dengue virus infections, CD $14^{+} \mathrm{CD} 16^{\text {bright }}$ proinflammatory monocytes were suggested to take on an important role, as they were shown to migrate to the draining lymph nodes where they encounter and activate antigen-specific memory B cells to differentiate into plasmablasts that secrete IgG and IgM [26]. Moreover, correlations with serum concentrations of IP-10 hinted at pro-inflammatory monocytes as 
the main producers of this chemokine [28]. We can confirm this correlation for the healthy controls only. However, in the patients, IP-10 correlated significantly with terminally differentiated cytotoxic $\mathrm{T}$ cells. We therefore postulate that IP-10, which is held responsible for the cytokine storm in critically ill patients, is produced by cytotoxic T cells [29-31].

In our study, immature neutrophils, characterized by a lack of CD16 expression, continuously increased over time, yet reached a significant difference compared to healthy controls only during late acute infection. Interestingly, a handful of longitudinal studies on hospitalized COVID-19 patients have shown that severity was associated with an increase in neutrophil numbers and that these numbers were persistently elevated, even at clinical recovery [32]. Even though we here did not assess severe cases, our findings also suggest an unresolved inflammation at a time when most immune parameters had returned to normal.

What was conspicuously absent in our study was any major alteration among $\mathrm{CD} 4^{+}$ $\mathrm{T}$ helper cell subpopulations, including $\mathrm{T}_{\text {regs. }}$. In contrast, there were significant changes among cytotoxic subpopulations, among them an elevated CD38 expression, suggesting activation over all disease phases analyzed. Moreover, we observed a significant increase in terminally differentiated $\left(\mathrm{CD}^{-} 7^{-}\right)$cytotoxic $\mathrm{T}$ cells during incubation, which gradually declined during later phases. In chronic HIV infection, this population was shown to be inefficient and to correlate with viral burden [33,34]. Clearly, its role in COVID-19 awaits further elucidation. An opposing trend-increase during acute infection-was observed for both the $\mathrm{CD}_{45 \mathrm{RA}}{ }^{+} \mathrm{CD} 38^{+} \mathrm{CD} 27^{+}$and $\mathrm{CD} 45 \mathrm{RA}^{+} \mathrm{CD} 127^{-} \mathrm{CD} 27^{+}$populations, reminiscent of gradual differentiation into stem cell memory (TSCM) and effector memory (TEMRA), respectively $[23,35]$. Finally, there was also a significantly increased fraction of PD-1 ${ }^{+}$ cytotoxic T cells during early acute infection. Even though PD-1 expression on SARS$\mathrm{CoV}-2$ specific $\mathrm{CD}^{+}$cells was previously associated with an activated phenotype [36], prolonged antigen stimulation and sustained expression of inhibitory receptors like PD-1 can ultimately lead to impaired $\mathrm{T}$ cell functionality and exhaustion [37].

As for significant alterations among the bulk populations of B cells, T cells, NK cells, and monocytes, during the early phases of COVID-19, we only observed T-lymphopenia, and this was more pronounced for the helper than the cytotoxic T cells. However, this drop in peripheral T cells was not paralleled by an increase in apoptotic cells, suggesting that, rather than being eliminated, T cells possibly relocated to the sites of infection or to lymphatic tissues. Of note, we did not observe any significant alteration among NK cells, neither among the bulk nor among subpopulations. Likewise, there were no alterations among monocyte/NK or monocyte/granulocyte ratios, which confirms previous findings about mild-to-moderate COVID-19 [32,38].

A major limitation of this study is the small sample size of COVID-19 patients. Additionally, not all patients were available for all consecutive venipunctures. We therefore propose that future studies should consider a study design in which shorter intervals for sample acquisitions are incorporated for a larger cohort. Furthermore, we did not document the participants' underlying health status and are therefore unable to assess whether co-morbidities affected the variance within and between groups. Finally, in contrast to what is shown in this study, delineation of acute disease phases on the basis of SARS-CoV-2 specific antibody dynamics only applies to primary infection, as convalescent patients would already have developed a humoral response prior to re-infection.

In summary, the present study defines a plasmablast-antibody landscape that defines different disease stages during mild-to-moderate COVID-19. These disease stages were further characterized by means of cellular parameters and identify the time frame where cytokinogenesis was most prominent. Upcoming research needs to focus on comparable disease stages during severe COVID-19 in order to allow for the identification of landmarks where resolution of viral infection segregates from progressing immune dysregulation and fatal outcomes. Moreover, as global efforts are underway to identify and develop new antiviral and immunomodulatory therapeutics that reduce COVID-19 related hospitalization and deaths, the need arises for the right timing [39]. Indeed, early type I IFN treatment seemed to be critical for therapeutic success [40]. However, prophylactic im- 
munomodulation might not be feasible for most COVID-19 patients due to high costs and potential adverse events. Therefore, identifying immunological landmarks will enhance a therapeutic potential towards benefits rather than harm.

Supplementary Materials: The following supporting information can be downloaded at: https: / / www.mdpi.com/article/10.3390/v14020203/s1, Figure S1: Exemplary gating scheme for the 24-color immune phenotyping of peripheral whole blood; Table S1: CD14+ Multi-Pathway Signaling; Table S2: CD3+ Multi-Pathway Signaling; Table S3: CD19+ Multi-Pathway Signaling; Table S4: CD11b+ Multi-Pathway Signaling; Table S5: Percentages of B cell Subpopulations; Table S6: Serum Antibodies; Table S7: Percentages of Monocyte Subpopulations; Table S8: Percentages of Granulocyte Subpopulations; Table S9: Percentages of CD8+ T Cell Subpopulations; Table S10: Expression of CD38 among CD8+ T Cell Subpopulations; Table S11: Percantages of CD4+ T Cell Subpopulations; Table S12: Percantages of NK Cell Subpopulations; Table S13: Serum Cytokines; Table S14: Absolute Numbers of Live Leukocytes; Table S15: Apoptotic among Live Leukocytes; Table S16: Correlations among Humoral and Cellular Immune Parameters in Healthy Controls; Table S17: Correlations among Humoral and Cellular Immune Parameters in COVID-19 Patients.

Author Contributions: Conceptualization, M.M., J.V. and B.M.-H.; methodology, M.M. and J.V.; validation, M.M., J.V. and B.M.-H.; formal analysis, M.M. and B.M.-H.; data curation, M.M. and B.M.-H.; writing—original draft preparation, J.V. and B.M.-H.; writing—review and editing, J.V., B.S., C.J.S., H.G.-F., E.C.R. and B.M.-H.; visualization, J.V. and B.M.-H.; supervision, B.M.-H.; funding acquisition, E.C.R. All authors have read and agreed to the published version of the manuscript.

Funding: This study was financially supported by the Federal State of Mecklenburg-Western Pomerania via the "Sondervermögen des MV Schutzfonds, Säule Gesundheit" (GW-20-0004) and the Ministry of Social Affairs, Health and Sports as well as the Ministry of Sciences, Culture, Federal and European Affairs.

Institutional Review Board Statement: The study was conducted in accordance with the Declaration of Helsinki, and was approved by Ethics Committee of the University Medical Center of Rostock (reference number A 2020-0086).

Informed Consent Statement: Informed consent was obtained from all subjects involved in the study.

Data Availability Statement: All data generated or analyzed during this study are included in this published article (and its Supplementary Information File).

Acknowledgments: We thank all our participants for taking part in this study and providing blood samples. The authors want to particularly thank Wendy Bergmann (Core Facility for Cell Sorting and Cell Analysis, Rostock University Medical Center) for help during flow cytometry panel design and setup and Micha Löbermann (Department of Tropical Medicine and Infectious Diseases, Rostock University Medical Center) for helping recruit Participants.

Conflicts of Interest: The authors declare that they have no conflict of interest.

\section{References}

1. Dong, E.; Du, H.; Gardner, L. An interactive web-based dashboard to track COVID-19 in real time. Lancet Infect. Dis. 2020, 20, 533-534. [CrossRef]

2. Muralidar, S.; Ambi, S.V.; Sekaran, S.; Krishnan, U.M. The emergence of COVID-19 as a global pandemic: Understanding the epidemiology, immune response and potential therapeutic targets of SARS-CoV-2. Biochimie 2020, 179, 85-100. [CrossRef] [PubMed]

3. Krause, P.R.; Fleming, T.R.; Longini, I.M.; Peto, R.; Briand, S.; Heymann, D.L.; Beral, V.; Snape, M.D.; Rees, H.; Ropero, A.-M.; et al. SARS-CoV-2 Variants and Vaccines. N. Engl. J. Med. 2021, 385, 179-186. [CrossRef] [PubMed]

4. Hall, V.J.; Foulkes, S.; Charlett, A.; Atti, A.; Monk, E.J.M.; Simmons, R.; Wellington, E.; Cole, M.J.; Saei, A.; Oguti, B.; et al. SARS-CoV-2 infection rates of antibody-positive compared with antibody-negative health-care workers in England: A large, multicentre, prospective cohort study (SIREN). Lancet 2021, 397, 1459-1469. [CrossRef]

5. Da Rosa Mesquita, R.; Francelino Silva Junior, L.C.; Santos Santana, F.M.; Farias de Oliveira, T.; Campos Alcântara, R.; Monteiro Arnozo, G.; Rodrigues da Silva Filho, E.; Galdino dos Santos, A.G.; Oliveira da Cunha, E.J.; Salgueiro de Aquino, S.H.; et al. Clinical manifestations of COVID-19 in the general population: Systematic review. Wien. Klin. Wochenschr. 2021, 133, 377-382. [CrossRef]

6. Napoli, C.; Benincasa, G.; Criscuolo, C.; Faenza, M.; Liberato, C.; Rusciano, M. Immune reactivity during COVID-19: Implications for treatment. Immunol. Lett. 2021, 231, 28-34. [CrossRef] 
7. Chen, G.; Wu, D.; Guo, W.; Cao, Y.; Huang, D.; Wang, H.; Wang, T.; Zhang, X.; Chen, H.; Yu, H.; et al. Clinical and immunological features of severe and moderate coronavirus disease 2019. J. Clin. Investig. 2020, 130, 2620-2629. [CrossRef]

8. Vabret, N.; Britton, G.J.; Gruber, C.; Hegde, S.; Kim, J.; Kuksin, M.; Levantovsky, R.; Malle, L.; Moreira, A.; Park, M.D.; et al Immunology of COVID-19: Current State of the Science. Immunity 2020, 52, 910-941. [CrossRef]

9. Wilk, A.J.; Lee, M.J.; Wei, B.; Parks, B.; Pi, R.; Martínez-Colón, G.J.; Ranganath, T.; Zhao, N.Q.; Taylor, S.; Becker, W.; et al. Multi-omic profiling reveals widespread dysregulation of innate immunity and hematopoiesis in COVID-19. J. Exp. Med. 2021, 218, e20210582. [CrossRef]

10. Boscolo-Rizzo, P.; Guida, F.; Polesel, J.; Marcuzzo, A.V.; Capriotti, V.; D’Alessandro, A.; Zanelli, E.; Marzolino, R.; Lazzarin, C.; Antonucci, P.; et al. Sequelae in adults at 12 months after mild-to-moderate coronavirus disease 2019 (COVID-19). Int. Forum Allergy Rhinol. 2021, 1-4. [CrossRef]

11. Logue, J.K.; Franko, N.M.; McCulloch, D.J.; McDonald, D.; Magedson, A.; Wolf, C.R.; Chu, H.Y. Sequelae in Adults at 6 Months After COVID-19 Infection. JAMA Netw. Open 2021, 4, e210830. [CrossRef]

12. Seeßle, J.; Waterboer, T.; Hippchen, T.; Simon, J.; Kirchner, M.; Lim, A.; Müller, B.; Merle, U. Persistent Symptoms in Adult Patients 1 Year After Coronavirus Disease 2019 (COVID-19): A Prospective Cohort Study. Clin. Infect. Dis. 2021, ciab611. [CrossRef]

13. Roussel, M.; Ferrant, J.; Reizine, F.; Le Gallou, S.; Dulong, J.; Carl, S.; Lesouhaitier, M.; Gregoire, M.; Bescher, N.; Verdy, C.; et al Comparative immune profiling of acute respiratory distress syndrome patients with or without SARS-CoV-2 infection. Cell Rep. Med. 2021, 2, 100291. [CrossRef]

14. Iannetta, M.; Buccisano, F.; Fraboni, D.; Malagnino, V.; Campogiani, L.; Teti, E.; Spalliera, I.; Rossi, B.; Di Lorenzo, A.; Palmieri, R.; et al. Baseline T-lymphocyte subset absolute counts can predict both outcome and severity in SARS-CoV-2 infected patients: A single center study. Sci. Rep. 2021, 11, 12762. [CrossRef]

15. McInnes, L.; Healy, J.; Melville, J. UMAP: Uniform Manifold Approximation and Projection for Dimension Reduction. arXiv 2018, arXiv:1802.03426.

16. Chen, N.; Zhou, M.; Dong, X.; Qu, J.; Gong, F.; Han, Y.; Qiu, Y.; Wang, J.; Liu, Y.; Wei, Y.; et al. Epidemiological and clinical characteristics of 99 cases of 2019 novel coronavirus pneumonia in Wuhan, China: A descriptive study. Lancet 2020, 395, 507-513. [CrossRef]

17. Moratto, D.; Chiarini, M.; Giustini, V.; Serana, F.; Magro, P.; Roccaro, A.M.; Imberti, L.; Castelli, F.; Notarangelo, L.D.; QuirosRoldan, E. Flow Cytometry Identifies Risk Factors and Dynamic Changes in Patients with COVID-19. J. Clin. Immunol. 2020, 40, 970-973. [CrossRef]

18. Kuri-Cervantes, L.; Pampena, M.B.; Meng, W.; Rosenfeld, A.M.; Ittner, C.A.G.; Weisman, A.R.; Agyekum, R.S.; Mathew, D.; Baxter, A.E.; Vella, L.A.; et al. Comprehensive mapping of immune perturbations associated with severe COVID-19. Sci. Immunol. 2020, 5, eabd7114. [CrossRef]

19. Mathew, D.; Giles, J.R.; Baxter, A.E.; Oldridge, D.A.; Greenplate, A.R.; Wu, J.E.; Alanio, C.; Kuri-Cervantes, L.; Pampena, M.B.; D'Andrea, K.; et al. Deep immune profiling of COVID-19 patients reveals distinct immunotypes with therapeutic implications. Science 2020, 369, eabc8511. [CrossRef]

20. Long, Q.-X.; Liu, B.-Z.; Deng, H.-J.; Wu, G.-C.; Deng, K.; Chen, Y.-K.; Liao, P.; Qiu, J.-F.; Lin, Y.; Cai, X.-F.; et al. Antibody responses to SARS-CoV-2 in patients with COVID-19. Nat. Med. 2020, 26, 845-848. [CrossRef]

21. Guo, L.; Ren, L.; Yang, S.; Xiao, M.; Chang, D.; Yang, F.; Dela Cruz, C.S.; Wang, Y.; Wu, C.; Xiao, Y.; et al. Profiling early humoral response to diagnose novel coronavirus disease (COVID-19). Clin. Infect. Dis. 2020, 71, 778-785. [CrossRef]

22. Sterlin, D.; Mathian, A.; Miyara, M.; Mohr, A.; Anna, F.; Claër, L.; Quentric, P.; Fadlallah, J.; Devilliers, H.; Ghillani, P.; et al. IgA dominates the early neutralizing antibody response to SARS-CoV-2. Sci. Transl. Med. 2021, 13, eabd2223. [CrossRef]

23. Appay, V.; Dunbar, P.R.; Callan, M.; Klenerman, P.; Gillespie, G.M.A.; Papagno, L.; Ogg, G.S.; King, A.; Lechner, F.; Spina, C.A.; et al. Memory CD8+ T cells vary in differentiation phenotype in different persistent virus infections. Nat. Med. 2002, 8, 379-385. [CrossRef]

24. Cooper, D.A.; Imrie, A.A.; Penny, R. Antibody Response to Human Immunodeficiency Virus After Primary Infection. J. Infect. Dis. 1987, 155, 1113-1118. [CrossRef]

25. Hampl, H.; Kapprell, H.P.; Sawitzky, D.; Wilske, W.; Gürtler, L. Detection of specific human immunodeficiency virus IgM antibodies. Med. Microbiol. Immunol. 1995, 184, 69-71. [CrossRef]

26. Green, A.M.; Harris, E. Monocyte-Plasmablast Crosstalk during Dengue. Cell Host Microbe 2014, 16, 7-9. [CrossRef]

27. Kazer, S.W.; Walker, B.D.; Shalek, A.K. Evolution and Diversity of Immune Responses during Acute HIV Infection. Immunity 2020, 53, 908-924. [CrossRef]

28. Kwissa, M.; Nakaya, H.I.; Onlamoon, N.; Wrammert, J.; Villinger, F.; Perng, G.C.; Yoksan, S.; Pattanapanyasat, K.; Chokephaibulkit, K.; Ahmed, R.; et al. Dengue Virus Infection Induces Expansion of a CD14+CD16+ Monocyte Population that Stimulates Plasmablast Differentiation. Cell Host Microbe 2014, 16, 115-127. [CrossRef]

29. Zhang, N.; Zhao, Y.-D.; Wang, X.-M. CXCL10 an important chemokine associated with cytokine storm in COVID-19 infected patients. Eur. Rev. Med. Pharmacol. Sci. 2020, 24, 7497-7505. [CrossRef]

30. Pasrija, R.; Naime, M. The deregulated immune reaction and cytokines release storm (CRS) in COVID-19 disease. Int. Immunopharmacol. 2021, 90, 107225. [CrossRef]

31. Lei, R.; Mohan, C. Immunological Biomarkers of COVID-19. Crit. Rev. Immunol. 2020, 40, 497-512. [CrossRef] [PubMed] 
32. Hazeldine, J.; Lord, J.M. Neutrophils and COVID-19: Active Participants and Rational Therapeutic Targets. Front. Immunol. 2021, 12, 2097. [CrossRef] [PubMed]

33. Ferbas, J.; Kaplan, A.H.; Hausner, M.A.; Hultin, L.E.; Matud, J.L.; Liu, Z.; Panicali, D.L.; Nerng-Ho, H.; Detels, R.; Giorgi, J.V. Virus Burden in Long-Term Survivors of Human Immunodeficiency Virus (HIV) Infection Is a Determinant of Anti-HIV CD8+ Lymphocyte Activity. J. Infect. Dis. 1995, 172, 329-339. [CrossRef] [PubMed]

34. Eller, M.A.; Goonetilleke, N.; Tassaneetrithep, B.; Eller, L.A.; Costanzo, M.C.; Johnson, S.; Betts, M.R.; Krebs, S.J.; Slike, B.M.; Nitayaphan, S.; et al. Expansion of Inefficient HIV-Specific CD8 T Cells during Acute Infection. J. Virol. 2016, 90, 4005-4016. [CrossRef] [PubMed]

35. Mahnke, Y.D.; Brodie, T.M.; Sallusto, F.; Roederer, M.; Lugli, E. The who's who of T-cell differentiation: Human memory T-cell subsets. Eur. J. Immunol. 2013, 43, 2797-2809. [CrossRef]

36. Rha, M.-S.; Jeong, H.W.; Ko, J.-H.; Choi, S.J.; Seo, I.-H.; Lee, J.S.; Sa, M.; Kim, A.R.; Joo, E.-J.; Ahn, J.Y.; et al. PD-1-Expressing SARS-CoV-2-Specific CD8+ T Cells Are Not Exhausted, but Functional in Patients with COVID-19. Immunity 2021, 54, 44-52.e3. [CrossRef]

37. Wherry, E.J.; Ha, S.-J.; Kaech, S.M.; Haining, W.N.; Sarkar, S.; Kalia, V.; Subramaniam, S.; Blattman, J.N.; Barber, D.L.; Ahmed, R. Molecular Signature of CD8+ T Cell Exhaustion during Chronic Viral Infection. Immunity 2007, 27, 670-684. [CrossRef]

38. Carsetti, R.; Quinti, I.; Locatelli, F. COVID-19-Pathogenesis and immunological findings across the clinical manifestation spectrum. Curr. Opin. Pulm. Med. 2021, 27, 193-198. [CrossRef]

39. Humphries, F.; Shmuel-Galia, L.; Jiang, Z.; Wilson, R.; Landis, P.; Ng, S.L.; Parsi, K.M.; Maehr, R.; Cruz, J.; Morales-Ramos, A.; et al. A diamidobenzimidazole STING agonist protects against SARS-CoV-2 infection. Sci. Immunol. 2021, 6, eabi9002. [CrossRef]

40. Bessière, P.; Wasniewski, M.; Picard-Meyer, E.; Servat, A.; Figueroa, T.; Foret-Lucas, C.; Coggon, A.; Lesellier, S.; Boué, F.; Cebron, N.; et al. Intranasal type I interferon treatment is beneficial only when administered before clinical signs onset in the SARS-CoV-2 hamster model. PLoS Pathog. 2021, 17, e1009427. [CrossRef] 